\title{
Acute coronary syndrome in a 100 -year-old woman treated successfully with primary percutaneous coronary angioplasty
}

\author{
Jarosław Karwowski', Maciej Bęćkowski', Hanna Szwed¹, Andrzej Ciszewski \\ $1^{\text {nd }}$ Department of Coronary Artery Disease, Institute of Cardiology, Warsaw, Poland \\ 2Department of Invasive Cardiology, Institute of Cardiology, Warsaw, Poland
}

Postep Kardiol Inter 2013; 9, 2 (32): 179-183

DOI: $10.5114 /$ pwki.2013.35456

\begin{abstract}
We present a case of a 100-year-old woman living alone with ST-elevation myocardial infarction acute coronary syndrome of the infero-lateral wall treated with percutaneous coronary intervention. Coronary angiography revealed critical $99 \%$ stenosis in the marginal branch of the circumflex artery and insignificant lesions in other arteries. Two bare metal stents were implanted successfully in the same session. The patient was discharged home in good general condition, able to live and function independently.
\end{abstract}

Key words: acute coronary syndrome, very elderly patients.

\section{Introduction}

Dynamic progress in medicine leading to extension of human life and demographic decline cause aging of the population. According to WHO data, the number of people 80 years of age and older is expected to increase almost fourfold by the year 2050. The number of patients at very old age with myocardial infarction is increasing according to data from acute coronary syndrome registries [1]. One of the challenges of modern cardiology is the optimal treatment of myocardial infarction in this group of patients, which remains difficult despite new diagnostic and therapeutic tools. Most randomized trials used as the background for the guidelines of management have excluded persons above 80 years of age, because of age or comorbidities. The lack of information on the efficacy and safety of interventional treatment of myocardial infarction accompanied by more frequent side effects and complications of treatment in patients at very old age may lead to abandonment or delay of proper treatment.

\section{Case report}

A 100-year-old woman with a history of arterial hypertension was referred for 24-hour hemodynamic monitoring from the emergency department of the regional hos- pital because of acute coronary syndrome. The patient reported typical chest pain lasting $10 \mathrm{~h}$ and preceded by 3 days of recurrent angina. Electrocardiogram showed STsegment elevation myocardial infarction (STEMI) of the infero-lateral wall. Physical examinations revealed regular heart rhythm of $55 \mathrm{bpm}$, arterial pressure of 150/80 mm Hg and presence of normal vesicular murmur without signs of lung congestion. In the admission room the patient received $180 \mathrm{mg}$ of ticagrelor and $300 \mathrm{mg}$ of aspirin per os and $500 \mathrm{ml}$ of Ringer solution intravenously. Unfractionated heparin (70 IU/kg i.v.) was administered in the emergency department of the referring hospital, but aspirin and clopidogrel were not given due to recurrent vomiting. The patient was immediately transferred to the catheterization laboratory. Laboratory examinations demonstrated anemia with $\mathrm{Hgb}$ of $9.6 \mathrm{~g} / \mathrm{dl}$, signs of renal impairment creatinine concentration of $1.27 \mathrm{mg} / \mathrm{dl}$, eGFR of $41.3 \mathrm{ml} /$ $\mathrm{min} / 1.72 \mathrm{~m}^{2}$ and elevated markers of myocardial necrosis - Tnl $0.247 \mathrm{ng} / \mathrm{ml}$ and CK-MB $8.1 \mathrm{ng} / \mathrm{ml}$. Coronary angiography demonstrated critical (99\%) stenosis of the marginal branch of the left coronary artery (MB LCA) and insignificant lesions in the left anterior descending artery and right coronary artery. This was followed by angioplasty of the critical stenosis consisting of initial predilation with a $2.5 \mathrm{~mm}$ balloon and subsequent $3.0 \mathrm{~mm} \times 15 \mathrm{~mm}$ bare

\section{Corresponding author:}

Jarosław Karwowski, 2nd Department of Coronary Artery Disease, Institute of Cardiology, 1 Spartańska St, 02-637 Warsaw, Poland,

tel.: +48 502913 169, e-mail: karwowski.jarek@gmail.com

Received: 17.12.2012, accepted: 9.05.2013. 
metal stent (BMS) implantation. Because of the dissection observed below the implanted stent a second BMS (2.5 mm $\times 12 \mathrm{~mm}, 12 \mathrm{~atm}$ ) was implanted. TIMI 3 flow in the infarct related artery was obtained. The patient was transferred to the intensive care unit (ICU), where echocardiographic examination was performed. The study showed dysfunction of the mid-ventricular and basal segments of the inferior and antero-lateral wall with akinesis of $1 / 3$ of these segments and left ventricular ejection fraction of $40 \%$. During the stay in the ICU the patient did not report any chest pain, did not have symptoms of heart failure and motor rehabilitation was initiated. The maximal concentration of the markers of ischemia on the $2^{\text {nd }}$ day was $93.651 \mathrm{ng} / \mathrm{ml}$ for $\mathrm{Tnl}$ and $155.7 \mathrm{ng} / \mathrm{ml}$ for CK-MB. The patient was transferred to the conservative unit. Despite intravenous hydration a transient increase of creatinine concentration to $2.29 \mathrm{mg} / \mathrm{dl}$ was observed on the $9^{\text {th }}$ day of hospitalization with a gradual reduction to $1.43 \mathrm{mg} / \mathrm{dl}$ at discharge. Because of the anemia an endoscopic examination was performed. It ruled out gastrointestinal bleeding. Echocardiographic examination on discharge showed hypokinesis of the previously akinetic segments with EF of $40 \%$. Due to the fact that the patient lived alone, motor rehabilitation was continued until achievement of full mobility. The patient was discharged home on the $17^{\text {th }}$ day of hospitalization in good general condition and capable of independent functioning (Figures 1 and 2).

\section{Discussion}

Early reperfusion therapy in STEMI in patients at very old age is effective and safe and improves prognosis in comparison to conservative treatment $[2,3]$. The choice between primary percutaneous coronary intervention and thrombolysis seems to be easy, especially in the era of very well-organized interventional treatment of myocardial infarction. Making the right decision is supported by the studies showing superiority of invasive treatment in all age groups and particularly in the elderly [4]. Besides, due to contraindications and fear of complications fibrinolytic therapy in patients above 80 years of age is used less often than indicated. Because of that fact, some patients without access to interventional treatment do not receive reperfusion therapy [3]. Percutaneous coronary intervention in the elderly is more challenging. However, if an experienced operator performs it in a large cath lab, the frequency of serious post-procedural complications is similar to the one observed in younger patients $[5,6]$. Due to a poorly palpable pulse on the radial artery in the present case, the procedure was performed via the femoral artery. Researchers conducting the multicenter RIVAL trial demonstrated that the choice of radial artery access decreases the frequency of local vascular complications such as large hematomas ( $1.2 \%$ vs. $3.0 \%)$ and pseudo-aneurysms requiring intervention ( $0.2 \%$ vs. $0.6 \%$ ) in comparison to a femoral approach at 30-day follow-up [7]. The choice of puncture site in patients at very old age is problematic, because the procedures are more technically difficult, particularly in women, who have lower diameter of the artery, higher tendency for vessel constriction and higher risk of peripheral vascular complications [8]. The study of Fenghuan Hu et al. [9] may be helpful in that matter. The authors compared the safety and efficacy of a transradial approach to a transfemoral approach in patients above 80 years of age undergoing primary percutaneous coronary intervention. The choice of a transradial approach was related to longer cannulation time $(3.0 \pm 2.8 \mathrm{~min}$ vs. $2.0 \pm 1.9 \mathrm{~min}, p<0.001)$ and fluoroscopy ( $23 \pm 15$ min vs. $19 \pm 12 \mathrm{~min}, p=0.03$ ), higher percentage of artery puncture failure ( $9.8 \%$ vs. $3.8 \%$, $p=0.02$ ) and statistically insignificant increase of the amount of contrast agent used $(227 \pm 48 \mathrm{ml}$ vs. $205 \pm 39$ $\mathrm{ml}, p=0.06)$. Despite that, patients who were treated with transradial access were less likely to have local bleeding ( $2.7 \%$ vs. $9.6 \%, p=0.004)$, hematoma ( $4.5 \%$ vs. $10.9 \%$, $p=0.006)$ or other vascular complications ( $7.1 \%$ vs. $23.7 \%$, $p<0.001)$ and had approximately fourfold shorter time of immobilization ( $5 \pm 2$ h vs. $20 \pm 4$ h), which is particularly important in reduction of the thrombo-embolic risk. There was no difference in the frequency of deaths, myocardial infarctions and repeated revascularizations during in-hospital follow-up. Jaffe et al. obtained similar results, but the transfemoral approach was related to a significantly lower dose of administered contrast agent ( $180 \pm 20 \mathrm{ml}$ vs. 224 $\pm 46 \mathrm{ml}, p<0.001$ ) [10]. Taking these studies into account as well as the patient's sex and age, signs of chronic kidney disease on laboratory examinations, and the tortuous and small radial artery on physical examination, the choice of a femoral approach seemed justified. It was demonstrated that stent implantation improves prognosis of elderly patients with myocardial infarction undergoing primary percutaneous coronary intervention [11]. Difficult decisions regard the choice of the stent type. The use of drug-eluting stents (DES) reduces the risk of restenosis and repeated revascularization in comparison to BMS [12], but on the other hand available randomized clinical trials comparing both types of stents in acute coronary syndromes were performed on preselected groups of younger patients. It is worth discussing the study of Marcolino et al., which has been recently published in Eurolntervention [13]. The researchers compared the efficacy and safety of DES in comparison to bare metal stents in patients above 80 years of age. Mortality rates and the risk of myocardial infarction were similar in both studied groups, but patients with DES had lower risk of repeated revascularization. Target lesion revascularization (TLR) was 9.5 vs. 0.6 per 1000 patient/years after 1 year and 3.4 vs. 0.7 per 1000 patient/years after 4 years. Important aspects regard the influence of cognitive disorders and low socio-economic status of the elderly patients on regular drug intake. According to the ESC guidelines and the Polish Society of Cardiology, predicted poor compliance regarding dual 

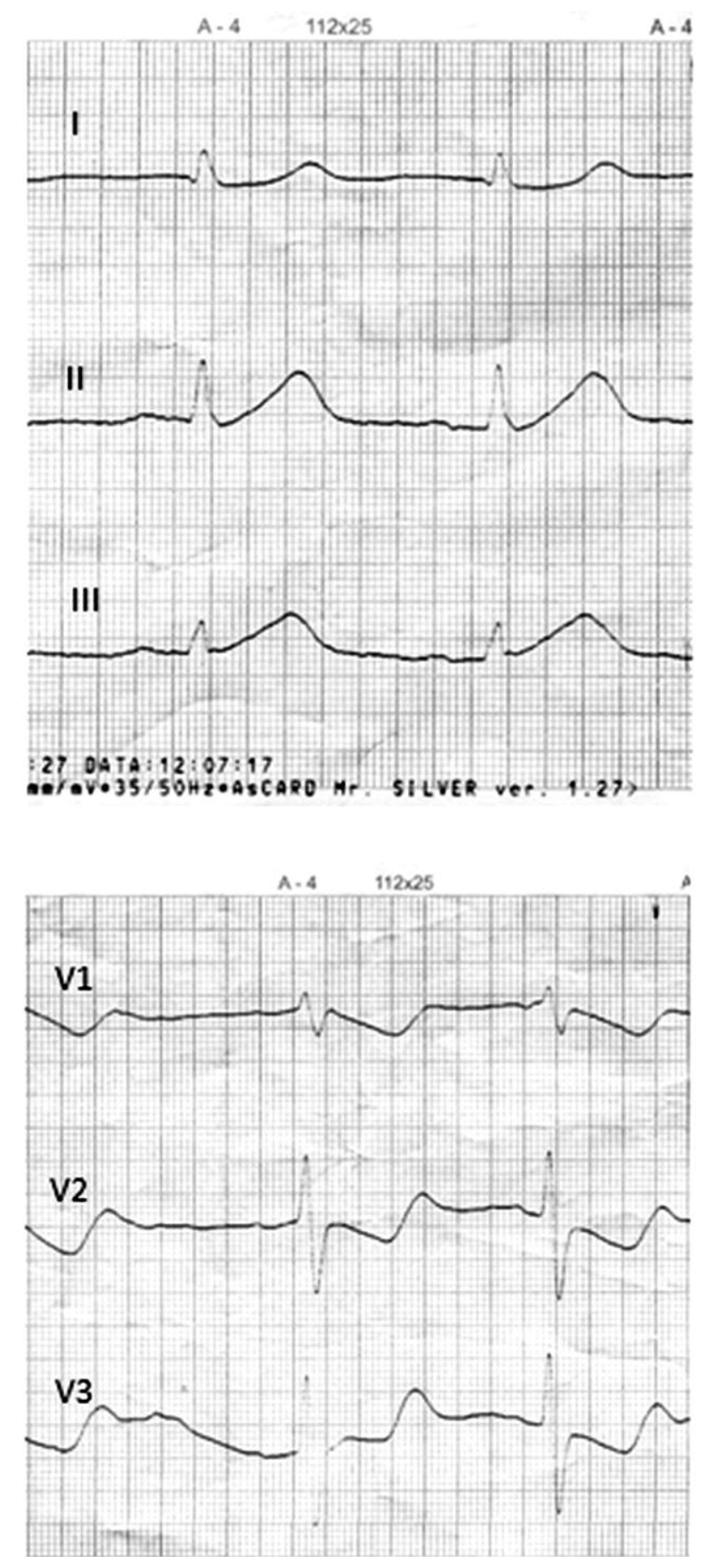

Fig. 1. First ECG after admission to primary hospital

antiplatelet treatment, including patients with numerous concomitant diseases and taking many drugs, is a relative contraindication to DES implantation [14]. We have presented a case of a 100-year-old female patient, living alone, for whom the probability of premature cessation of dual antiplatelet therapy is high and would be much more dangerous in the case of DES implantation. Despite the welldeveloped network of 24-hour service of catheterization laboratories and highly experienced interventional cardi-
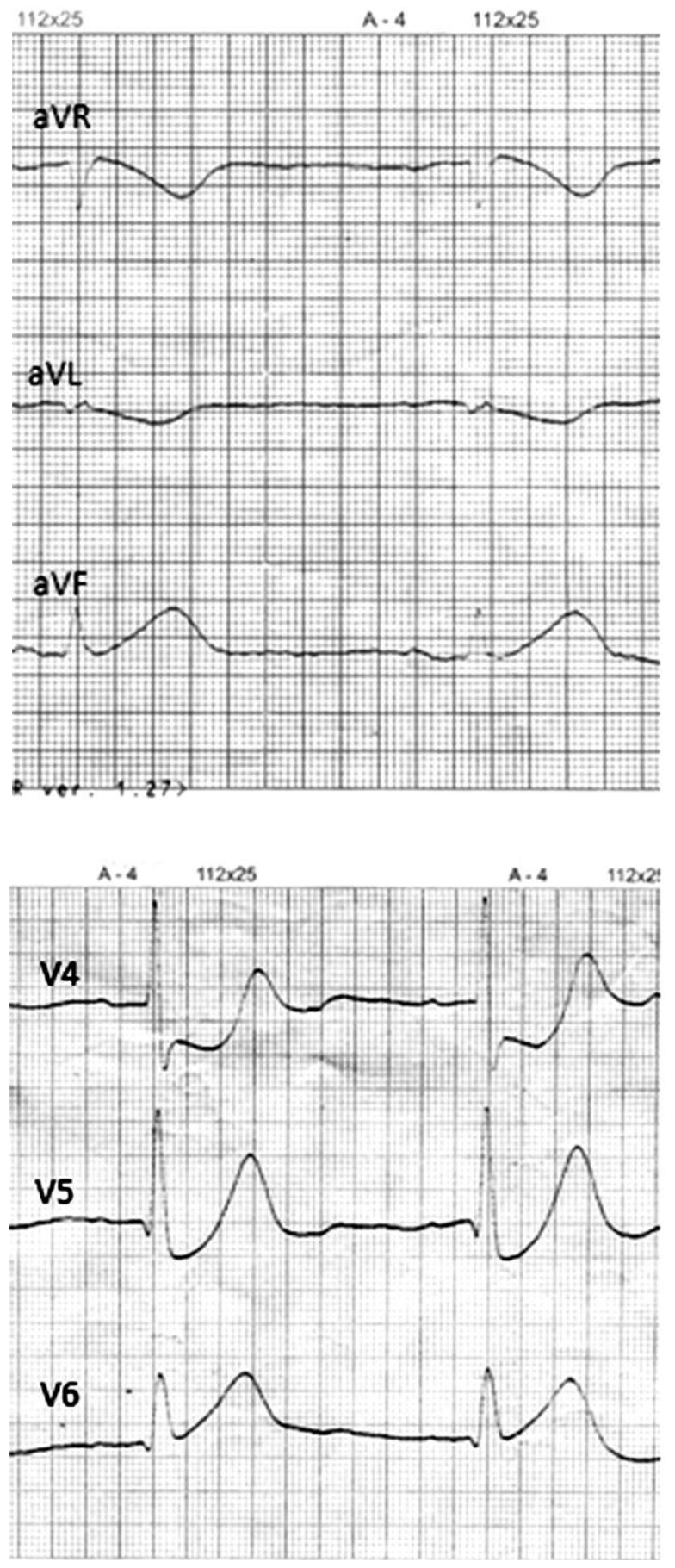

ologists, the results of treatment of elderly patients are unsatisfactory. The prognosis is significantly worse in comparison to younger patients, while in-hospital and 1-year mortality are approximately 3 -fold higher $[5,6]$. One of the causes is certainly a higher frequency of concomitant diseases in this group of patients including heart failure, respiratory diseases, previous cerebrovascular episodes and renal failure. The prognosis of patients at very old age is also worsened by the longer time between the onset of 

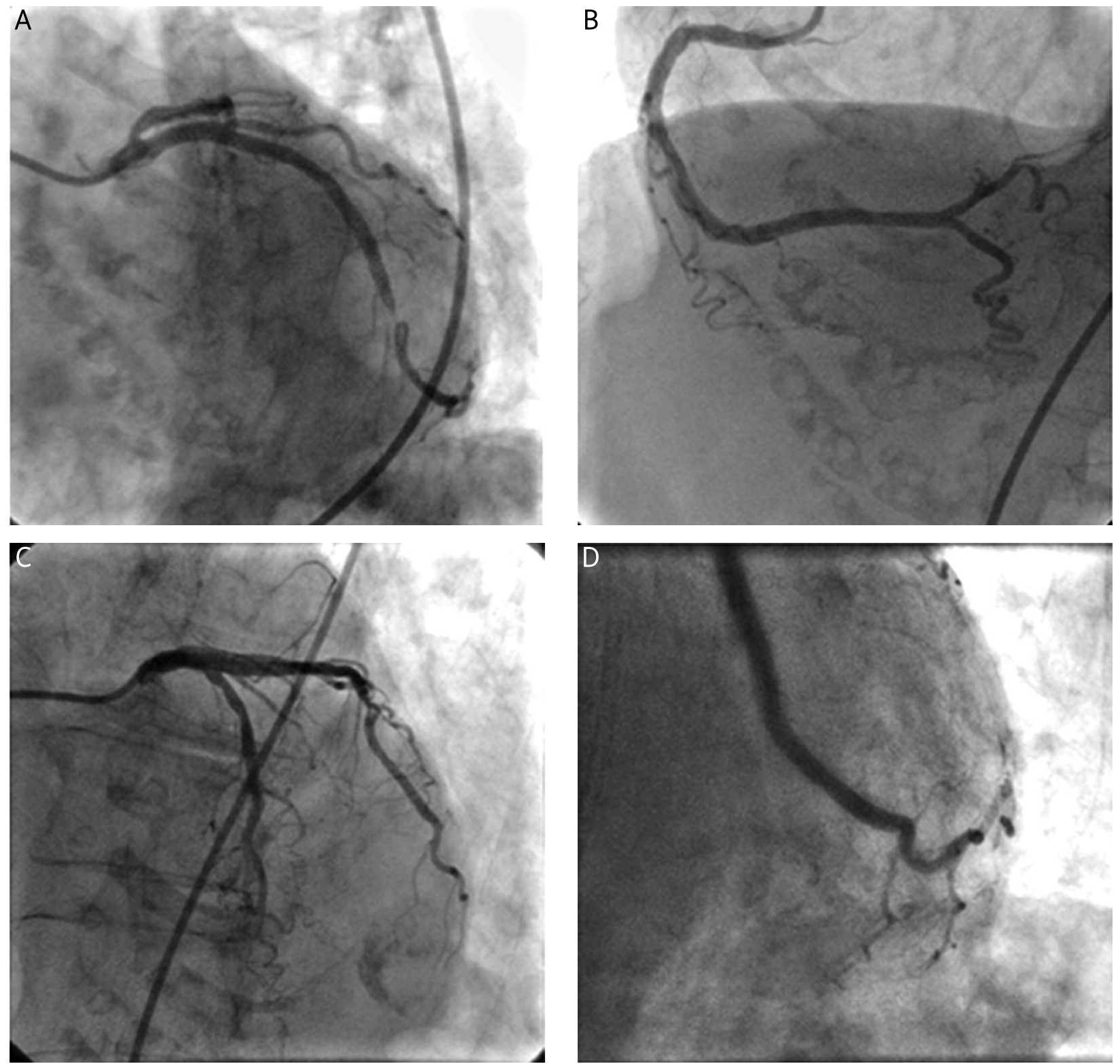

Fig. 2. Coronary angiography during STEMI of the infero-lateral wall. Critical $99 \%$ stenosis in the marginal branch of circumflex artery (A) and insignificant lesions in RCA (B) and LAD (C). The marginal branch after implantation of 2 BMS (D)

symptoms and initiation of treatment. This is influenced by a lower perception of chest pain and more frequent occurrence of atypical pain or other non-specific symptoms of angina in comparison to younger patients [15]. Diagnostic difficulties are also caused by abnormalities in the baseline ECG such as persistent ST-segment elevation or left bundle branch block (LBBB), which hamper the interpretation of ischemic changes [16]. In order to accelerate the antiplatelet effect the patient received a loading dose of $180 \mathrm{mg}$ of ticagrelor with subsequent switching from ticagrelor to a maintenance dose of clopidogrel in the following days. Was this approach the right decision? The patient did not receive adequate antiplatelet treatment at the time of diagnosis, because of vomiting. It has been established that the antiplatelet effect of ticagrelor is faster and the degree of platelet aggregation inhibition is higher [17]. An analysis of patients above and below 75 years of age participating in the PLATO trial demonstrated that clinical benefits of the new drug are comparable in both groups (including reduction of the composite end-point consisting of cardiovascular death, myocardial infarction and stroke and reduction of individual end-points such as stroke, myocardial infarction, cardiovascular death and instent thrombosis). There was no increase of serious bleeding in the elderly [18]. On the other hand, the results of the RESPOND trial showed that switching from ticagrelor (ini- 
tial dose of $180 \mathrm{mg}$ followed by $90 \mathrm{mg}$ twice daily) to clopidogrel (initial dose of $600 \mathrm{mg}$ followed by $75 \mathrm{mg}$ daily) after 14 days of treatment resulted in increase of the platelet aggregation from $36 \pm 14 \%$ to $56 \pm 9 \%$ [19]. The choice of ticagrelor was in line with the ESC guidelines recommending new antiplatelet drugs [20]. Switching to clopidogrel before discharge was determined by lack of reimbursement of the drug and financial constraints of the patient. Until now there have been no studies on the switching between $\mathrm{P} 2 \mathrm{Y} 12$ platelet receptor inhibitors in patients at very old age.

\section{Conclusions}

Because of the demographic situation and easy access to a large network of catheterization laboratories on duty, an increase of the number of patients at very old age referred for interventional treatment of acute coronary syndrome may be expected. It is the management of choice in this group of patients, as conservative treatment is mostly unsuccessful and is related to high mortality. The choice of arterial access, type of implanted stent and adequate peri-procedural pharmacotherapy should be made after consideration of individual risks and benefits of the patient. Primary percutaneous coronary intervention performed by an experienced interventional cardiologist is safe.

\section{References}

1. Gąsior M, Zembala M, Poloński L, et al. Elderly with acute coronary syndrom - an increasing clinical problem. Kardiol Pol 2006; 64: 1154-1157.

2. Medina HM, Cannon CP, Fonarow GC, et al. Reperfusion strategies and quality of care in 5339 patients age 80 years or older presenting with ST-elevation myocardial infarction: analysis from get with the guidelines-coronary artery disease. Clin Cardiol 2012; 35: 632-640.

3. Rymuza H, Kowalik I, Drzewiecki A, et al. Successful primary coronary angioplasty improves early and long-term outcomes in ST segment elevation acute coronary syndromes in patients above 80 years of age. Kardiol Pol 2011; 69: 346-354.

4. Holmes Jr DR, White HD, Pieper KS, et al. Effect of age on outcome with primary angioplasty versus thrombolysis. J Am Coll Cardiol 1999; 33: 412-419.

5. Ciszewski A, Karcz M, Kępka C, et al. Primary angioplasty in patients $\geq 75$ years old with ST-elevation myocardial infarction one-year follow-up results. Kardiol Pol 2008; 66: 828-833.

6. Kochman W, Prokopczuk P, Dobrzycki S, et al. Acute myocardial infarction in the elderly treated with primary coronary angioplasty. Folia Cardiol 2002; 9: 443-450.

7. Jolly SS, Yusuf S, Cairns J, et al. Radial versus femoral access for coronary angiography and intervention in patients with acute coronary syndromes (RIVAL): a randomised, parallel group, multicentre trial. Lancet 2011; 377: 1409-1420.

8. Gwon HC, Doh JH, Choi JH, et al. A 5Fr catheter approach reduces patient discomfort during transradial coronary intervention compared with a $6 \mathrm{Fr}$ approach: a prospective randomized study. J Interv Cardiol 2006; 19: 141-147.
9. Hu F, Yang Y, Qiao S, et al. Comparison between radial and femoral approach for percutaneous coronary intervention in patients aged 80 years or older. J Interv Cardiol 2012; 25: 513-517.

10. Jaffe $R$, Hong $T$, Sharieff $W$, et al. Acomparison of radial versus femoral approach for percutaneous coronary interventions in octogenarians. Catheter Cardiovasc Interv 2007; 69: 815-820.

11. Singh M, Mathew V, Garratt KN, et al. Effect of age on the outcome of angioplasty for acute myocardial infarction among patients treated at the Mayo Clinic. Am J Med 2000; 108: 187-192.

12. Stettler C, Wandel S, Allemann S, et al. Outcomes associated with drug-eluting and bare-metal stents: a collaborative network metaanalysis. Lancet 2007; 370: 937-948.

13. Marcolino MS, Simsek C, de Boer SP, et al. Short- and long-term outcomes in octogenarians undergoing percutaneous coronary intervention with stenting. Euro Interv 2012 pii: 20110717-01.

14. Wijns W, Kolh P, Danchin N, et al. The Task Force on Myocardial Revascularization of the European Society of Cardiology (ESC) and the European Association for Cardio-Thoracic Surgery (EACTS); European Association for Percutaneous Cardiovascular Interventions (EAPCI). Eur Heart J 2010; 31: 2501-2555.

15. Rittger H, Rieber J, Breithardt OA, et al. Influence of age on pain perception in acute myocardial ischemia: a possible cause for delayed treatment in elderly patients. Int J Cardiol 2011; 149: 63-67.

16. Rogers WJ, Bowlby LJ, Chandra NC, et al. Treatment of myocardial infarction in the United States (1990 to 1993). Observations from the National Registry of Myocardial Infarction. Circulation 1994; 90: 2103-2114.

17. Gurbel PA, Bliden KP, Butler K, et al. Randomized double-blind assessment of the ONSET and OFFSET of the antiplatelet effects of ticagrelor versus clopidogrel in patients with stable coronary artery disease: the ONSET/OFFSET study. Circulation 2009; 120: 2577-2585.

18. Husted S, James S, Becker RC, et al. Ticagrelor versus clopidogrel in elderly patients with acute coronary syndromes: a substudy from the prospective randomized PLATelet Inhibition and Patient Outcomes (PLATO) trial. Circ Cardiovasc Qual Outcomes 2012; 5: 680-688.

19. Gurbel PA, Bliden KP, Butler K, et al. Response to ticagrelor in clopidogrel nonresponders and responders and effect of switching therapies: the RESPOND study. Circulation 2010; 121: 1188-1199.

20. Steg PG, James SK, Atar D, et al. ESC Guidelines for the management of acute myocardial infarction in patients presenting with ST-segment elevation: The Task Force on the management of ST-segment elevation acute myocardial infarction of the European Society of Cardiology (ESC). Eur Heart J 2012; 33: 2569-2619. 